\title{
The Implications of Potential "Lock-In" in Markets for Renewable Energy
}

Robin Cowan and David Kline

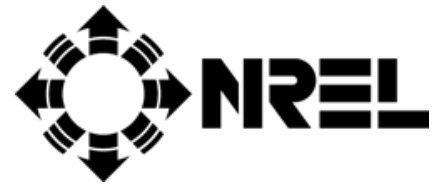

National Renewable Energy Laboratory 1617 Cole Boulevard

Golden, Colorado 80401-3393

A national laboratory of the U.S. Department of Energy Managed by Midwest Research Institute for the U.S. Department of Energy under contract No. DE-AC36-83CH10093 


\section{The Implications of Potential "Lock-In" in Markets for Renewable Energy}

Robin Cowan and David Kline

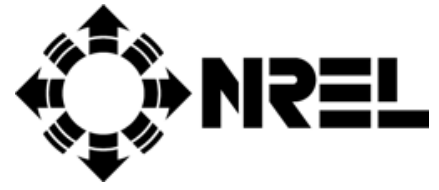

National Renewable Energy Laboratory 1617 Cole Boulevard

Golden, Colorado 80401-3393

A national laboratory of the U.S. Department of Energy Managed by Midwest Research Institute for the U.S. Department of Energy under contract No. DE-AC36-83CH10093

Prepared under Task No. AS027241

November 1996 


\section{NOTICE}

This report was prepared as an account of work sponsored by an agency of the United States government. Neither the United States government nor any agency thereof, nor any of their employees, makes any warranty, express or implied, or assumes any legal liability or responsibility for the accuracy, completeness, or usefulness of any information, apparatus, product, or process disclosed, or represents that its use would not infringe privately owned rights. Reference herein to any specific commercial product, process, or service by trade name, trademark, manufacturer, or otherwise does not necessarily constitute or imply its endorsement, recommendation, or favoring by the United States government or any agency thereof. The views and opinions of authors expressed herein do not necessarily state or reflect those of the United States government or any agency thereof. 


\section{Contents}

Page

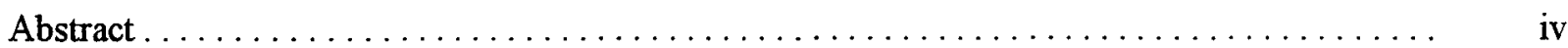

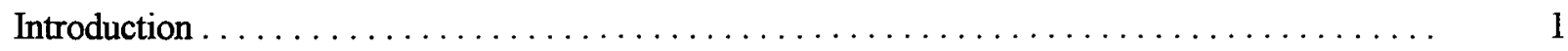

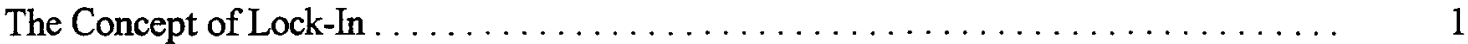

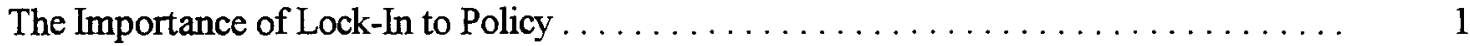

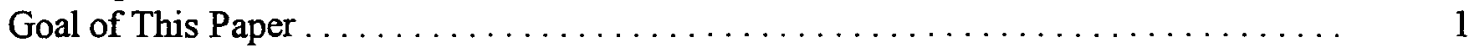

The Influence of Increasing Returns on Market Dynamics $\ldots \ldots \ldots \ldots \ldots \ldots \ldots \ldots \ldots$

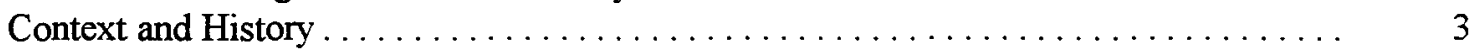

Market Outcomes . . . . . . . . . . . . . . . . . . . . . . . . . . . . . 3

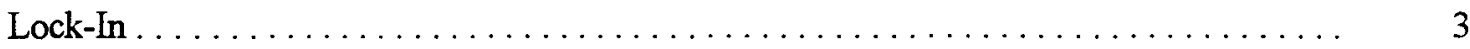

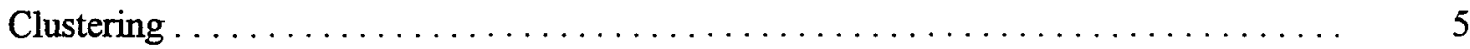

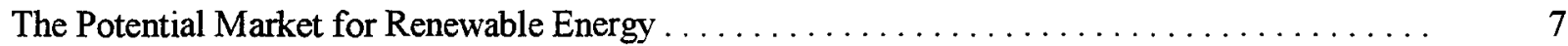

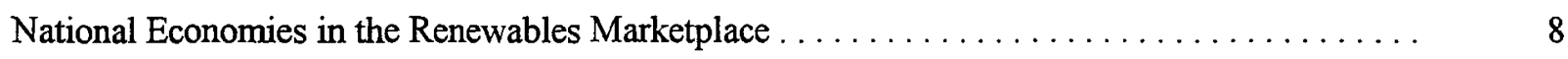

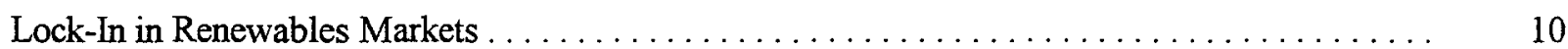

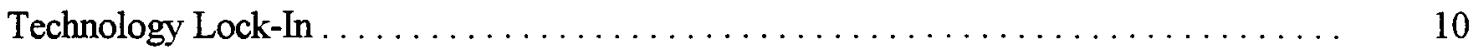

Clustering in Renewables Markets . . . . . . . . . . . . . . . . . . . . . . . 11

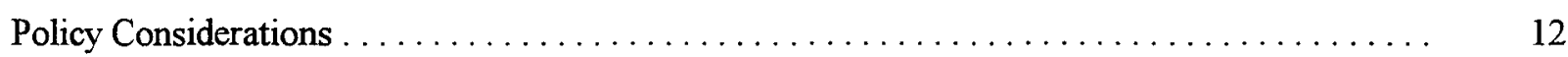

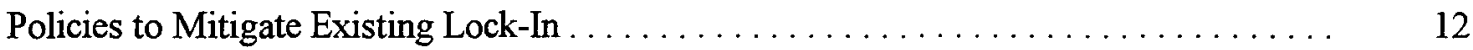

Policy Implications of Clustering $\ldots \ldots \ldots \ldots \ldots \ldots \ldots \ldots \ldots \ldots \ldots \ldots \ldots \ldots \ldots \ldots \ldots$

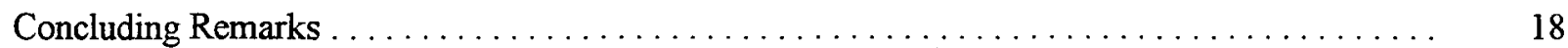

References . . . . . . . . . . . . . . . . . . . . . . . . . . . . . . 


\begin{abstract}
Nonlinear economic effects-increasing returns in particular-can cause unpredictable and sometimes undesirable outcomes in the marketplace. Until recently, however, these effects were largely ignored in mainstream economic theory. This paper explores the implications of recent work in this area for renewable energy markets, and for policy toward these markets.

Increasing returns can lead to a self-reinforcing situation, in which increasing market share leads to a more attractive product, which leads in turn to further increases in market share. This "virtuous circle," if carried far enough, results in the "lock-in" of that technology. Once lock-in occurs, no existing technology can effectively compete. The lock-in can be overcome only by a significant shift in technology, consumer tastes, or other market factors.

Lock-in applies to renewable markets in two ways: First, conventional technologies, such as fossil-fueled electric generating technologies, are already locked in. As a result, renewable technologies will have difficulty penetrating the market even when they are cheaper than conventional alternatives. There are several possible escapes from this kind of lock-in, and some can be exploited by appropriate policy instruments.

Lock-in can also apply to the market share of a supplier of a given technology. This kind of outcome may have even more sweeping effects. We discuss the potential that foreign suppliers of renewable energy technologies could capture the global market, locking it in so that suppliers outside the leading country find it very difficult to compete. We consider the attributes of renewable energy markets that make them susceptible to this kind of supplier lock-in, and suggests strategies to address this possibility. One striking conclusion is that the domestic renewables market could play a key role in the success of firms in competing for global market share.
\end{abstract}




\section{Introduction}

Economists have long known that nonlinear effects can cause complicated and sometimes undesirable outcomes in the marketplace. Increasing returns can result in very different results from the textbook cases, which generally assume decreasing returns. During the past 10 years, some economists have focused increasingly on the details of these dynamics, recognizing that increasing returns are a feature of many manufactured goods in modern economies. This paper will consider the implications of one of these phenomena, known as "lock-in," for renewable energy markets, and will consider the role of policy in view of this effect.

\section{The Concept of Lock-In}

Lock-in emerges from the details of nonlinear market dynamics. The basic dynamic is quite simple: For several reasons, the choice of one of several market alternatives by one buyer can often increase the probability that the next buyer will also choose that alternative. In many circumstances, the choice of one technology can be selfreinforcing to the point where it completely dominates the market.

One oft-cited example, described by Arthur (1990), is the early competition in the videocassette recorder market. This market began with two competing formats: VHS and Betamax. In the early stages of the competition, both products exhibited increasing returns: An increase in market share for one VCR format tended to increase the availability of prerecorded tapes in that format, thereby increasing the value of owning a player for that format and further increasing its market share. As it turned out, early gains by VHS were amplified by this positive feedback, which eventually led to its overwhelming market share. This kind of initially unstable market can "choose" an inferior technology over a superior one due to chance events in the early history. (Some have argued that the inferior technology was selected in the battle between VHS and Betamax.)

\section{The Importance of Lock-In to Policy}

The observation that an inferior technology can become locked in has several implications for policy. ${ }^{1}$ In renewable energy markets, these considerations lead us to consider two distinct possibilities: First, conventional technologies already have locked in many energy markets, making penetration by alternatives such as renewable technologies difficult, even when they are superior. Second, the success of a supplier in a given market can also become self-reinforcing, especially when innovation and learning are significant. This paper considers the possibility that suppliers in one country might capture global renewable technology markets by this mechanism; it also considers possible responses to this possibility.

\section{Goal of This Paper}

This paper seeks to identify the policy implications of potential lock-in in renewable energy markets. These considerations will help provide a rationale for an element of technology policy that deals actively with these markets. Policy directions will emerge from the consideration of both lock-in by a technology and lock-in by a supplier.

The ideas are applicable to a wide range of renewable and efficiency technologies, but this paper focuses on renewable electric generation applications. It contains the following sections:

- The Influence of Increasing Returns on Market Dynamics, which introduces some basic concepts

1 Cowan (1991) shows how markets can choose an inferior technology, even under tight control by a central agency. 
- The Potential Market for Renewable Energy, which provides a brief survey of projections that illustrate the potentially large markets for renewable electric generation in the next several decades

- National Economies in the Renewables Marketplace, which reviews the status quo in these markets, revealing some suggestions of incipient supplier lock-in

- Lock-In in Renewables Markets, which considers the potential dynamics of renewable electric generation markets in further detail, considering both types of potential lock-in mentioned above

- Policy Considerations, which considers the policy implications of these market dynamics

- Concluding remarks. 


\section{The Influence of Increasing Returns on Market Dynamics}

\section{Context and History}

Most standard models of market equilibrium in economics are based on assumptions of decreasing returns. The central efficiency results - the neoclassical mathematical proofs of the virtues of the Invisible Hand-rely strongly on assumptions of decreasing returns to scale and related assumptions about consumer tastes.

Economists have known about situations involving increasing returns since the earliest formalization of economic thought, but only recently have serious investigations of increasing returns found their way into mainstream economic discussion. Beginning in the early 1980 s, Brian Arthur and others began to seriously explore the ramifications of situations in which increasing returns play a significant role. Not surprisingly, the results differ radically from the cases in which decreasing returns dominate. The key results under increasing returns can be described as inefficiency results: the marketplace can choose an inferior technology over a superior one when lock-in is a possibility.

Arguments based on these considerations recently received increasing public attention when they were used as part of the antitrust case against Microsoft Corporation's proposed acquisition of Intuit, Inc. Not surprisingly, the advancement of this argument produced a vociferous critique from advocates of a laissez faire, free market policy. ${ }^{2}$ To evaluate this debate on its merits, we now explore the implications of increasing returns in some detail.

\section{Market Outcomes}

In a market in which increasing returns are present, several issues that concern market dynamics can arise. In the context of the dynamics of the market for renewable energy technologies, two issues concern us: the possible lock-in of an existing technology, and the clustering of activities that surround the development and production of these technologies, which leads to groups of suppliers who capture a large fraction of the market.

\section{Lock-In}

The literature on technology competitions has focused attention on the possibility that a technology can become so entrenched that it is virtually impossible for the market to challenge its dominant position. This phenomenon is often called technological lock-in.

New technologies typically have three properties: First, users do not understand their value. Second, manufacturers do not understand how to produce them well. Third, there is considerable scope for improvement in performance. The third feature implies that there is typically a period in which they improve rapidly as more is learned about them. Learning by doing and learning by using, both of which take place only as the technology is employed, imply that the more a technology is used, the more improvements are made to it. As it improves, it becomes more attractive to potential users, which implies that more adopt it, and it is used more. This is a virtuous circle. The snowballing effect that follows can lead to the dominance of one technology: An early lead can grow to be incontestable, simply because once a technology gets ahead, more has been learned about it, it has improved more than its competitors, and is more attractive to future users. In short, the technology becomes locked in.

2 The lock-in argument used in the Microsoft/Intuit case is presented in Reback et al. (1996). The conservative reaction is expressed in Margolis and Liebowitz (1996). 
Of course it need not be the best technology that becomes locked in. For example, if early users have idiosyncratic needs (as the U.S. Navy needed a compact, light reactor that would be operational quickly), this can give a (globally) suboptimal technology an early lead in use and thus in improvement, such that alternatives cannot compete.

Figure 1 illustrates another way in which an inferior technology can be chosen when increasing returns are present. The figure illustrates two learning curves, giving unit cost as a function of cumulative production for two competing technologies. As the market develops, participants see only the current costs of each technology, not the entire curve. At time A, the technologies have sold the same number of units. Then technology $\mathrm{X}$ gains market share, because its cost is now lower. This of course decreases the cost of technology $X$ even further. By time $E$, technology $Y$ is driven from the marketplace. However, technology $\mathrm{Y}$ has a lower cost when fully developed, and it might have been preferable to adopt this technology.

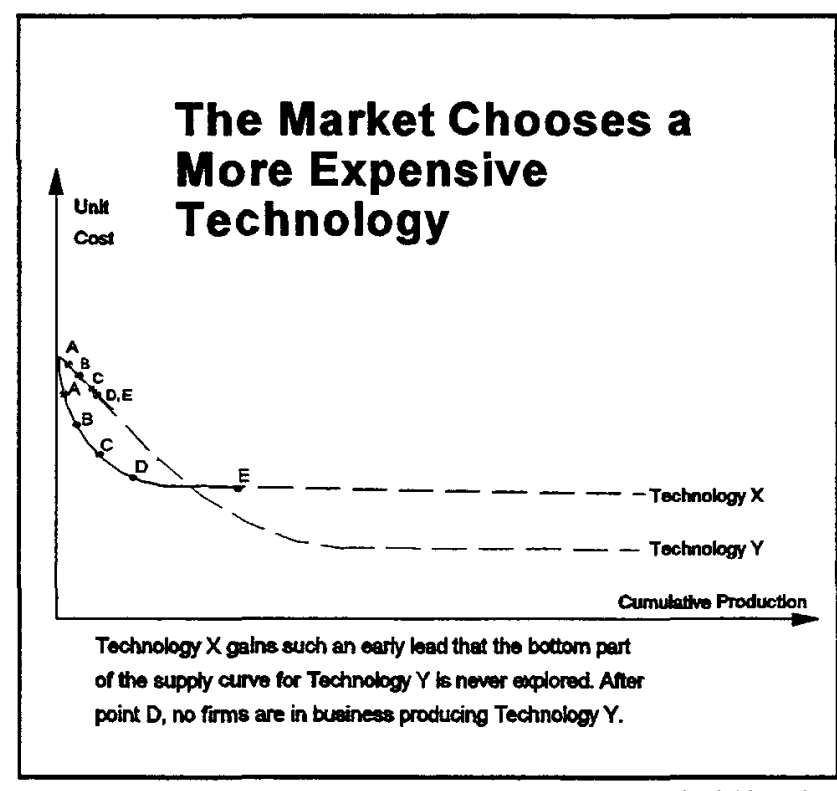

Figure 1

Source: Hypothetical Situation

The uncertainty about the characteristics of new technologies can also lead to lock-in. As technologies are used, experience resolves these uncertainties. The technology's performance characteristics come to be understood, so the net benefits of using it are learned. Thus, early in a competition, technology use has an aspect of information gathering - finding out which one is best. Experience with a technology increases the confidence with which its value can be estimated. When these confidence levels are high, there will be consensus about which is best, and it will become the dominant technology. Again, it need not be the best that is locked in. An early string of bad luck with a good technology (it was badly implemented, badly or carelessly produced, or hit some freak conditions) will drive down our estimates of its value. We switch to an inferior technology, thinking that it might be better. If our luck with it is average, we will stick with it. Thus an erroneous early estimate of the value of a superior technology, and average experience with an inferior one, can lead to the dominance of the less desirable one. Experience tells us how good the inferior one is, but no experience that would improve our estimates of the value of the better one is being accumulated.

Another class of phenomena that can foster lock-in is what economists call network externalities. ${ }^{3}$ Here, increasing penetration of a technology enhances the value of that technology to other consumers. For example, the more people there are on a telephone network, the more people can be reached by phone, and the more valuable phone service becomes. Network externalities occur in physical networks, such as telephone systems, and in other situations where supporting infrastructure or technology standardization is important. Often both network externalities and learning-curve effects are important in creating lock-in.

3 The term network externalities arose from the study of communications networks, which often exhibit this phenomenon. The use of the term externality reflects the fact that one consumer's choices influence other consumers' preferences, as in the telephone network example discussed below. 
This type of analysis also applies to a situation where a new technology is introduced, or an old one is reintroduced. Because new technologies often have the potential for significant improvement, we can expect that later generations will provide higher payoffs than do initial generations. Thus early users of a technology provide benefits for later users, both in bearing the costs of experimentation to find out "just how good it is" and in providing the experience that allows improvements to it. Of course, there is little incentive to provide this service to later users of a technology. It is risky and the costs may be high. No one wants to be the first user of a new technology. This makes it difficult for a new technology to break in to a market. Thus, positive feedbacks can introduce a certain type of inflexibility into an economy. It can become difficult for an economy, no matter how dynamic in other senses, to make major changes to its technological regime.

\section{Clustering}

Economists have long been aware that economic activity tends to cluster geographically. This idea has again been picked up in economic analysis, and extended and expanded. ${ }^{4}$ There are two related explanations for clustering: the need for specialized inputs, and the importance of knowledge spillovers.

\section{Specialized Inputs}

In a simple manufacturing industry, clustering is driven by markets for key inputs. Cutlery manufacturers need a certain type of steel, and fashion designers need button makers. It clearly makes sound economic sense to have good sources of these inputs nearby. This kind of consideration leads to clusters of activity, as cutlery makers all want to locate near the best steel makers, and as fashion designers locate near the most progressive button makers (or more probably vice versa). The simple idea here is that costs of manufacturing fall for every firm in the industry as the industry grows. These external effects are geographically localized to an extent that we can observe clusters of like manufacturers locating near each other.

In a knowledge-intensive industry, in which innovation, $R \& D$, and technical change are important, other types of specialized inputs exist. Feldman (1994) discusses the importance of patent lawyers, firms doing market research and feasibility studies, testing laboratories, and the presence of appropriate financial capital, all of which make product development easier. In any industry that has several layers of production, the presence of firms in other layers can be vital both through learning by using activities (Von Hippel 1988), and through the availability of specialized inputs.

\section{Knowledge Spillovers}

In new or knowledge-intensive industries, where R\&D is important, clustering is generated by knowledge production. Recent work shows that this clustering can exist independently of clustering in production. A large body of work now shows that there are significant knowledge spillovers in R\&D intensive industries ${ }^{5}$ These studies have several robust, general results. First, when measuring the degree to which the R\&D or technical innovation of one firm can be of use to another firm, geographic distance is very important. The farther firms are apart from each other, the less they can take advantage of each others' knowledge generation activities. This is true both when firms wish to share information and when they do not. Jaffe (1989) suggests that the distance over which knowledge "spills" is smaller than the size of a state.

4 See for example Arthur (1991), David and Rosenblum (1990), and Krugman (1992).

5 See for example Jaffe (1989), Jaffe et al. (1993), Glaeser et al. (1992), Prevezer and Swann (forthcoming) or Audretsch and Feldman (1994). 
Second, when trying to take advantage of the R\&D of another firm, it is more important to be geographically close to it than it is to be in the same industry. If two firms are in related (but not identical) industries, then knowledge spillovers are important if they are physically close together. Finally, even though knowledge spillovers create clustering in both innovative and industrial activity, the degree of concentration of innovation in an industry is positively related to the degree to which the industry is information intensive. We can see two reasons why innovative activity would cluster. The first is that much knowledge, particularly in industries that operate on the knowledge frontier, is tacit; It is not written down, but rather embedded in facilities, structures, and people. This means that transmission of it, if it takes place at all, is difficult, and takes place most effectively through face-to-face communication. ${ }^{6}$ Even when it is possible to codify knowledge, and write it in a form that makes it easy to send to others, significant difficulties in exchanging technical information remain, and these difficulties can drive clustering. The literature on technology development discusses these issues in some detail (Rosenberg [1990]; Cohen and Levinthal [1989]; Gambardella [1992]; Pavitt [1993]). A large body of literature documents the fact that even when two firms want to share knowledge, there are high costs of doing so (Williamson 1985; Teece 1981; Teece et al. 1988, for example). The difficulties are much greater, of course, if one firm is trying to prevent the other from using its knowledge.

A nicely documented example in a situation in which the agents are in principle sharing and actively diffusing their information occurred during the development of the laser. Collins et al. (1987) show that after reading the published accounts of how the first lasers were constructed, no one could duplicate the project. Only after talking with the scientists involved in the original work were others able to build lasers of their own. This example shows that even good documentation may be an insufficient basis for technology transfer. Significant amounts of tacit knowledge (often know-how) are needed to be able to understand what is written down or built. Industries in which information and know-how are important inputs are more subject to this kind of pressure toward clustering.

\section{Clustering as Lock-In}

If we think of different locations as competing with each other to attract participants in the industry, we can see that the tendency toward clustering can lead to a form of locational lock-in. The discussion in the previous paragraphs suggests several important sources of increasing returns to locational choices. Thus if one location gets ahead, it will look better than other locations in those regards. This will drive down the costs at that site, and attract more activity to it, which is a feedback of the type that creates a self-reinforcing system. This is the same kind of process that drives technological lock-in. It is thus possible that the geographic pattern of production can become locked in, and after that change only very slowly.

We now turn to a discussion of how the concepts of technology lock-in and clustering —or supplier lock-inapply to renewable energy. We begin with a brief overview of renewable energy markets.

6 Of eight ways of acquiring knowledge, technical workers ranked "visit knowledgeable person more than 20 miles away" last in preference (Sweeney 1987, p. 138, quoting Rosenberg 1967). The probability of two people communicating at least once a week is about 0.98 percent if their locations are 2 meters apart, but falls to 0.06 percent at a distance of 50 meters (Sweeney 1987, p.141). 


\section{The Potential Market for Renewable Energy}

Renewable technologies face an uncertain future marketplace. As shown in Figure 2, the range of estimates for the value of the renewable electric market is quite wide.

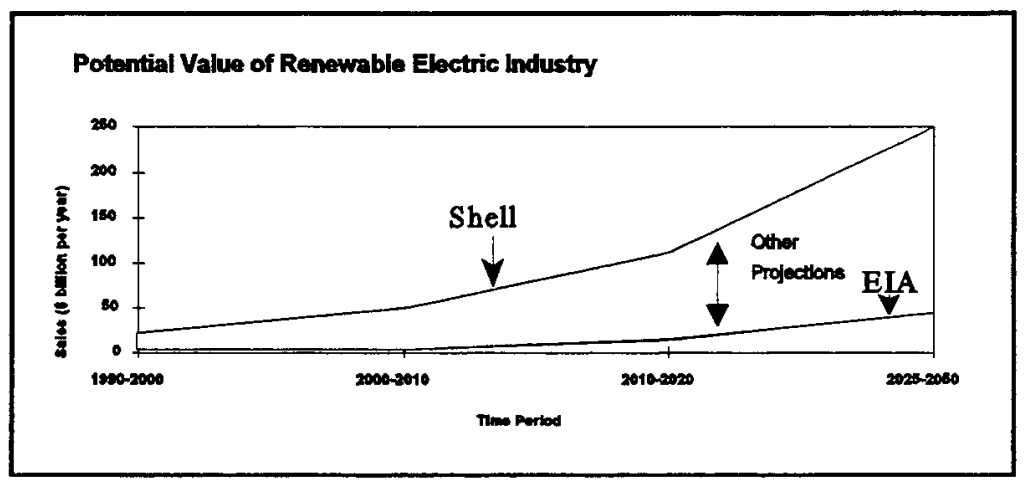

Source: Johansson et al. (1995), Shell (1995), U.S. DOE (1995)

Figure 2
The top of the range in Figure 2 is derived from a recent scenario developed by Shell. EIA (1996) provides a very conservative estimate, shown at the bottom of the range in Figure 2. Even using EIA's conservative figures, the renewables market worldwide will amount to some $\$ 10$ billion per year by the year 2010. Several studies, including Shell's, project renewables markets an order of magnitude larger than this. ${ }^{7}$ A complete consideration of the markets for village power and other applications not connected to utility grids could increase these estimates substantially.

The wide range of forecasts for renewables represents our first hint that they may be subject to positive feedback and thus to lock-in. Markets prone to lock-in are difficult to predict, because the outcome depends strongly on factors that are very difficult to measure. Further, small differences in assumptions made in the predictionassumptions about, for example, growth rates of energy demand, rates of technological progress, the price of oil-can be magnified into large differences in the outcomes of the process. Because, as we will see presently, renewable technologies have characteristics that make them prone to lock-in, it is difficult to predict the outcome of either the competition between renewables and conventional technologies, or the competition between competing renewable technologies. It is also difficult to predict the outcome of ongoing competition between suppliers of emerging technologies. This difficulty in particular has strong implications for renewable energy markets.

7 BTM 1995; Johannsson et al. 1993; Kassler 1994; WEC 1993. 


\section{National Economies in the Renewables Marketplace}

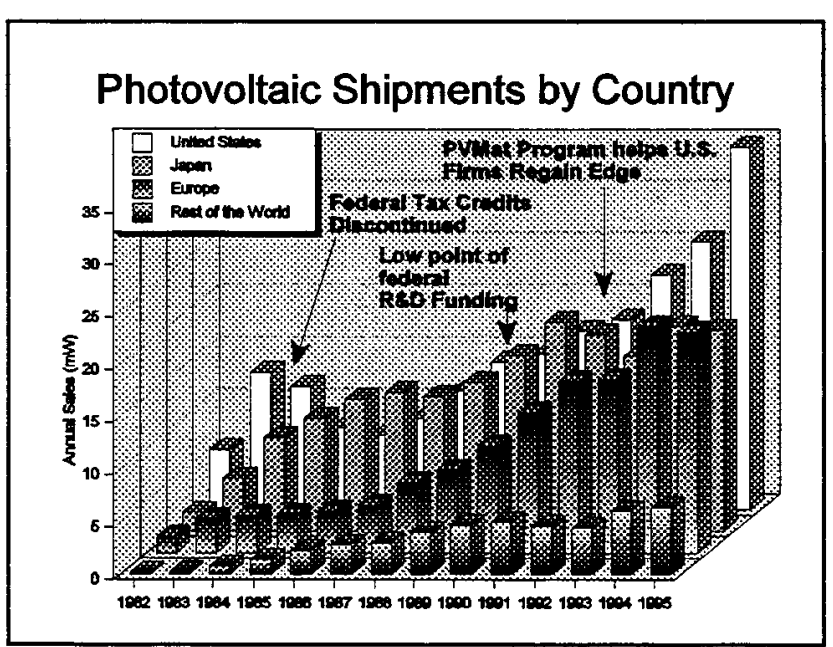

Figure 3

Source: $P V N e w s$, various issues
Figure 3 illustrates the recent history of world photovoltaics (PV) supply markets. This history illustrates two important points about renewables markets. First, the market is concentrated: The combined market share of U.S. and Japanese firms has never been less than $60 \%$, and has been increasing during the past few years. At the same time, market shares have fluctuated significantly. The United States and Japan have traded places as the world leader twice since 1982. U.S. market share has been insignificantly low (before the period shown in Figure 3), and reached a peak in the early $1980 \mathrm{~s}$, at more than $60 \%$. In 1995, U.S. firms supplied $42 \%$ of the world PV market.

Figure 4 shows the evolution of the U.S. market share of the PV industry over time. The graph also includes U.S. government R\&D budget for PV technology, suggesting that $R \& D$ efforts have a significant impact on the market for this rapidly changing, knowledge-intensive technology. We will return to the issue of R\&D strategy presently.

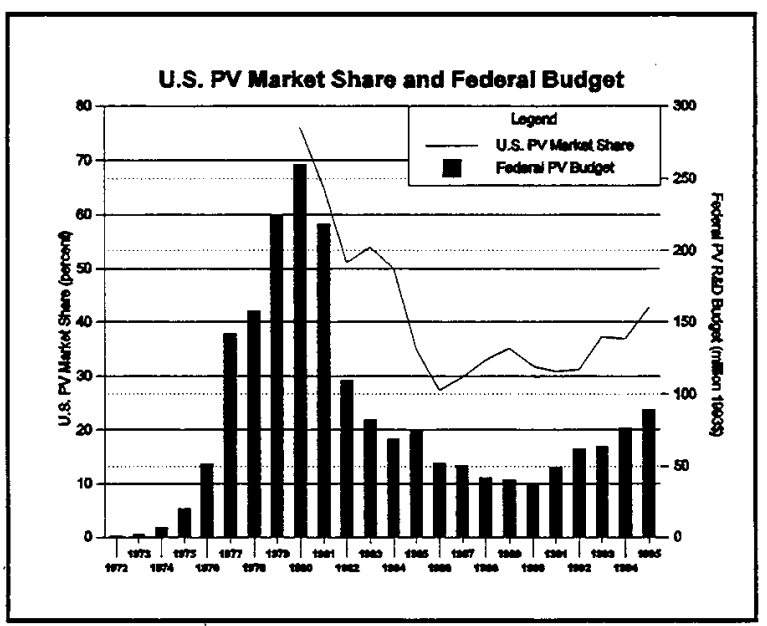

Figure 4
Source: $P V$ News, NREL 
Figure 5 describes the international wind market. ${ }^{8}$ Here we see what may be the beginning of supplier lock-in by one country. Although the United States has maintained a significant market share in wind power, Danish manufacturers have been the dominant producers in this market, partly because of significant Danish government support. Recent events, which might come under the heading of "historical accidents," cast significant doubt on U.S. prospects in this competitive marketplace. ${ }^{9}$

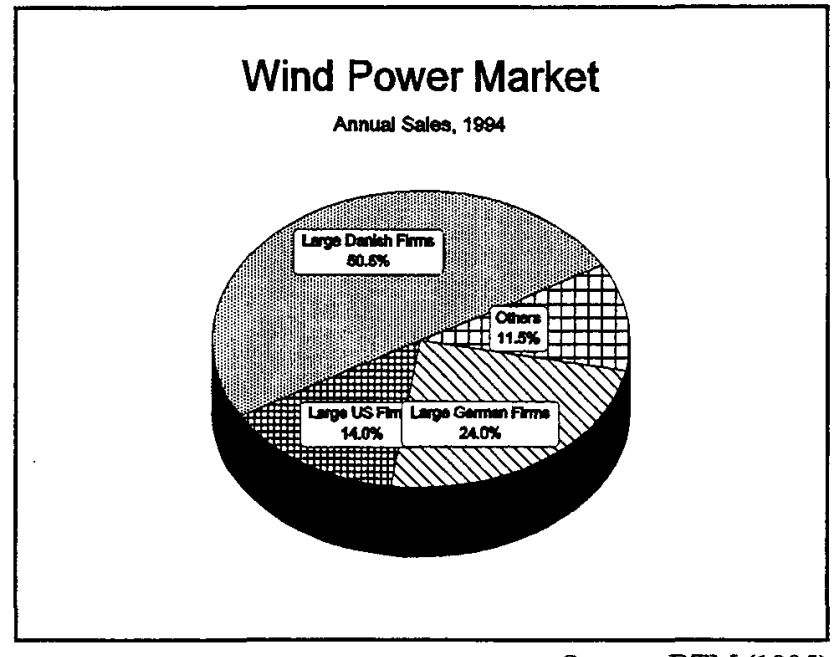

Figure 5

Source: BTM (1995)

8 The figures for Danish, German, and U.S. firms include only firms within the top 12 in 1994 wind power sales. All others are included under "other," including some smaller firms from these three countries.

9 The term historical accident borrows from the title of a paper by Brian Arthur, and describes "random" events in the early history of a market which, under lock-in dynamics, can have significant impacts on the eventual outcome. In this case, the only U.S. firm included in the 12 largest producers in 1994 was Kenetech, which held about $15 \%$ of the world market. During 1995, Kenetech turbines experienced a number of technical problems. A loss of confidence led to a $90 \%$ decline in the value of Kenetech's stock and a severe cash-flow crisis, raising the prospect of bankruptcy for the firm. 


\section{Lock-In in Renewables Markets}

Two points from the discussion just above have important implications when we consider renewable energy markets from the point of view of positive feedback and lock-in. First, the markets are potentially very large (Figure 2). Second, these markets are unstable, as leading technologies, firms, and countries change rapidly (e.g., as seen in Figure 3). Thus, the competition is ongoing in these markets. These market characteristics suggest that renewable energy markets are still malleable. At this early stage, they may be amenable to strategic influence, but at later stages they may not be.

This observation in turn reinforces the strategic importance of $R \& D$ efforts on renewable energy for two reasons: First, R\&D can have significant impacts during the stages of technology development in which technologies are rapidly changing and improving, and during which market patterns are still being established (Figure 4). Second, $R \& D$ efforts can produce intellectual property that can be at least partially protected, and thus put to the service of the national economy.

\section{Technology Lock-In}

Lock-in of existing technologies clearly exists in today's energy markets, and examples are easy to find. Cowan (1990), and Cowan and Hulten (1996) discuss two: the dominance of the light water reactor in the nuclear power market, and the lock-in of the internal-combustion, gasoline-powered automobile in the personal transportation market. Although we take these established technologies for granted today, both had serious competitors in earlier phases of their respective markets.

Fossil-fueled technologies in the electricity sector can also be seen to be locked in. These conventional technologies enjoy the benefits of a long history of efficiency improvements that have reduced the unit cost of electricity by several orders of magnitude. (For a fascinating recounting of this technology history, and how it led indirectly to serious financial problems in the utility sector during the 1970s, see Hirsh [1989].)

Many renewable technologies are at a stage of rapidly decreasing costs, and a good case can be made that costs could be decreased much further with economies of scale, and perhaps more importantly with cumulative production experience. ${ }^{10}$ The lock-in of conventional technologies persists partly because there is no way for future renewables users, who would benefit from lower costs, to compensate early adopters of renewables, who would have to pay higher costs.

Uncertainty also plays a role in maintaining the lock-in of conventional technologies. Because conventional generating technologies have such a long history and are so well understood, the relative uncertainty about the attributes of renewable technologies creates a barrier to entry. As seen in Cowan (1991), competitive markets will provide less than the optimal amount of experimentation with less-well-known alternatives. Anecdotal evidence from renewable markets also suggests that experimentation is undersupplied in these markets. Although experimentation with emerging technologies would yield valuable information, there is no market mechanism to compensate early adopters of renewables for providing this information.

This uncertainty can also contribute to difficulty in financing renewables projects. Renewables projects rely to a great extent on project financing provided by outside investment banking concerns. Uncertainty about future technology performance, and about future market size, can make this external financing more difficult to obtain. In addition, firms in the renewables industries tend to be small and have little credit history. These conditions

10 See WEC (1993) and Johansson et al. (1993), for example. 
can lead to an imperfectly functioning credit market that also decreases the amount of "experimentation" with renewable and energy-efficiency technologies.

In addition, several policies, designed primarily for other purposes, help maintain the lock-in of established energy technologies. In the United States, for example, conventional technologies receive many significant direct and indirect subsidies, and special tax treatment. In addition, regulatory treatment of the electric utility sector has tended to discourage experimentation with emerging technologies. The restructured, more competitive electricity industry will do little to improve the outlook for renewables in this respect.

\section{Clustering in Renewables Markets}

Renewable technologies also have several characteristics that suggest that manufacturing and related $R \& D$ for these technologies may cluster in a few locations. While clustering is not visible in many of these industries currently, there are several reasons to suspect that it could develop as these markets expand.

First, many of these technologies are currently experiencing periods of rapid learning: costs are dropping and performance is increasing. ${ }^{11}$ As we have argued above, rapid learning can promote lock-in; it can lead to the lockin of a leading manufacturer as well as a leading technology among competing alternatives.

Second, renewable technologies are knowledge-intensive. For example, wind turbines rely on specially designed blades constructed of specialized materials. Wind turbines also require sophisticated control systems to operate in varying wind regimes (and even to survive in the peak wind conditions that occur at good wind sites). PV manufacturers face many subtle materials-handling issues in constructing modules, and the quest for lower PV costs continues to push this envelope. Other renewable technologies also face difficult and specialized technical problems. Where this degree of specialized knowledge is required, communities of technical workers tend to develop, and to cluster in small geographic regions, as discussed above.

Many renewable technologies are also in an early stage of development. During these stages of rapid progress, specialized and often tacit knowledge- human capital-plays an especially large role in keeping a firm competitive in the marketplace. The importance of knowledge increases the value of locating near other firms that produce the same technology, thereby increasing the tendency toward clustering.

Interactions with users of renewable technologies will continue to be a key source of improvements in the technologies. The importance of this interaction will be enhanced by the fact that renewable resources differ significantly between regions. Thus, experience in one region may not be easily transferable to other localities. This inherent regionality could lead to its own form of clustering, or it could reinforce clusters of manufacturers already formed by other considerations.

We can see, then, that renewable energy markets are potentially subject to two significant types of lock-in: the existing lock-in of conventional energy technologies, and the prospective lock-in of renewable energy suppliers. Each of these market dynamics has significant implications for policy.

11 See Johansson et al. (1993), WEC (1993), World Bank (1994). 


\section{Policy Considerations}

\section{Policies to Mitigate Existing Lock-In}

Several closely related difficulties impede the introduction of a new technology. One difficulty is coordination. In some situations, benefits can be gained from changing technologies but the benefits only accrue if everyone makes the change. There can be sequencing problems, though, since no one wants to be the first to switcheveryone has to switch at once. This is a simple illustration of network externalities. The role for policy here is obvious and has been used successfully in several cases. To increase exports and decrease the price of cars during the 1960 s, Sweden switched from driving on the left-hand side of the road to driving on the right. It was done on a single day. ${ }^{12}$ Railroads in the southern United States changed the gauge of 14,000 miles of track in a single weekend. The U.S. army was brought out to help. (See also Cowan and Gunby [1996] for a discussion of similar coordinating policies in agricultural pest control.)

The second difficulty in switching is learning or dynamic increasing returns. The issue here is not one of coordination, but that the alternative (non-locked-in technology) is underdeveloped. Any agent who switches to a new technology, even if there is no coordination issue, will suffer through a period of low payoffs while the technology is improved. Market participants individually perceive this period of low returns to be a cost that is larger than the benefit of switching to the alternative (presumably superior) technology.

The third difficulty contributes to the second. As discussed, the problem with switching to a new technology is that the early users pay the development costs, from which all future users benefit. But there is no market mechanism by which the future users can compensate the early users for the costs of developing the technology. This will be a problem especially if the technology turns out to be long lived (such as the automobile). Thus the absence of a market can create a situation in which even though the total "costs" of switching technologies (costs in terms of the early adopters suffering through a period of low payoffs, that is) are small relative to the total benefits of a global switch, the economy is stuck on an old technology. Again, policy can be used to mitigate this effect of a missing market.

Finally, there may be other causes of inertia in the technological system. In energy markets, there may be externalities; e.g., we suddenly know about greenhouse gases, but no one is paying for the damage they do. (A tax on pollutants also creates an incentive to change the technology.) Another reason has to do with the social discount rate. There is also a standard argument that the social discount rate is lower than the market rate. This difference makes investments that the market sees as unprofitable the right thing to do from the social point of view. ${ }^{13}$ This is sometimes called the "future generations argument."

The arguments given in the previous paragraph are familiar market failure arguments, which apply in the absence of lock-in effects. However, in the context of lock-in, the focus does change. The mechanics of market lock-in make it difficult for a new, and potentially superior technology to enter the market, not only for traditional reason, but also because of dynamic increasing returns. These market barriers are unlikely to fall of their own accord.

12 In fact, to make sure that as many people as possible switched sides of the road at the same time, the switch was undertaken not in the middle of the night, as one might at first think, but at rush hour. For a theoretical discussion of this sort of phenomenon see Farrell and Saloner (1985).

Baumol (1995) makes a case for government support of R\&D in environmental control technologies, broadly construed, precisely along these lines. 
This discussion suggests that there are serious difficulties in overturning an entrenched technology. It may be extremely difficult for renewable energy technologies to find a significant presence in the market, optimistic forecasts of Shell notwithstanding. But new technologies do penetrate locked-in markets in some cases. Generalizing from a variety of case studies, there are six factors that can contribute to overturning a (quasi)lock-in, and several of them have implications for policy. ${ }^{14}$

\section{Crisis in Existing Technology}

The entrenched technology starts to fail. That is, it cannot perform the expected functions for some reason, or the costs of using it go up. This is currently not an issue for energy technologies, so policy considerations are not affected by this possible means of escape from lock-in.

\section{Regulation}

Regulation has often been used: (1) as a coordinating device to make it possible for all agents to coordinate their technology choices and take advantage of externality effects (see for example Cowan and Gunby [1996]); and (2) as a forcing mechanism, e.g., the California Air Resources Board clean air/auto pollution legislation in California, which requires the introduction of low-pollution vehicles.

In dealing explicitly with an existing lock-in situation, policy makers could simply write legislation similar in spirit to the California automobile emission legislation. This is easiest to justify (and obtain consent to) in the case of pure coordination. In such a case all will be immediately better off, but only if all make the switch. ${ }^{15}$

\section{Technological Breakthroughs}

This possibility can be thought of as a reduction in the cost of using the emerging technology. An imagined one allowed the entry of nuclear power into the generation of electricity (Cowan 1990); a real one allowed integrated pest management to be used in the Israeli citrus industry (Cowan and Gunby 1996); a real one allowed a change in the technology of ferrous casting in Germany (Foray and Gruebler 1993). Technological breakthroughs may be occurring in renewable energy as new technologies emerge and old ones are improved.

Policy cannot produce technological breakthroughs, but it can facilitate them. ${ }^{16}$ It can support research directly, both basic research into materials and technological infrastructure done in open research institutions such as universities and national laboratories, ${ }^{17}$ and more applied research into product types and generic technologies. Policy can also make potential breakthroughs more profitable. Here other aspects of policy come into play. Breakthroughs are profitable when the costs of producing them are relatively small, and the benefits are relatively

14 This section draws on Cowan and Hulten (1996).

15 Cases that are close to pure coordination are legislation concerning the agricultural methods used by cotton growers in Texas and North Carolina (separately); and in the citrus industry in Israel.

16 See Babiuch et al. (1996).

17 See Tassey (1992). 
large. There may be policies that implicitly favor the existing technology. ${ }^{18}$ Estimates of implicit subsidies to energy technologies suggest that renewable energy technologies are at a disadvantage in this respect.

\section{Niches}

A market niche dedicated to a new technology can help, but it must display specific features if it is to encourage strong penetration of the new technology. The niche must be a dynamic one. It must have active users putting pressure on producers to improve the product, and developing their own innovations. (This feeds point 3 above.) The niche must be outward looking - trying to attract new demanders on the one side, and looking outside for sources of innovations and cost reductions on the other.

Policy can create market niches. For example, most sales of electric vehicles in Europe are to municipalities. In a similar way, government could simply buy power from renewables in places where renewables are inexpensive, nonrenewables are expensive, or the environment is sensitive (which implies that the social cost of nonrenewables is high). Policy can also support niches less directly. For example, Nutech is an agency in Sweden whose mandate is to bring together demanders and suppliers of new technologies. It provides many services such as technology assessment (testing and information provision), which is costly early in the life of a technology. ${ }^{19}$

"Green Marketing" programs provide another way to exploit the niche idea. These programs function essentially by brokering contracts between users who want environmentally sensitive energy and developers of renewable energy projects. This brokering can take a variety of forms. The goal is to increase the viability of particular niches, namely those that express a strong demand for "green" energy. If the program successfully fosters this niche among users who have a very strong desire, the learning and scale effects in production will lower the costs of renewable energy, attracting users with weaker demand for environmental friendliness to adopt the technology.

\section{Changes in Taste}

If users preferences change, they may want a technology that has different features. This will provide an opportunity for new technologies that are very efficient in servicing the new tastes. A possible example of such a phenomenon is the new Web computer being marketed by Oracle and others that could potentially challenge the dominant personal computer technologies.

The scope for policy here is limited. This role should probably be restricted to providing information. Sometimes this provision is passive, for example by maintaining a database on technologies, who is developing them, how the market is evolving, and so on. At other times the information provision should be active. We have in mind here how a policy maker might respond to point 6 , below. If new scientific discoveries have implications for the social costs of various technologies, this information should be made public. It can be the case that no individual agent has the incentive to do so, in which case the role falls to policy.

18 Agricultural policies such as set-aside payments are often based on yield. This is not an issue if all technologies effectively maximize yield. But if a technology is economically superior but has lower yield, it is at a disadvantage under the policies based on yield.

19 Later in the life of a technology, assessment becomes much less important as there has been enough experience that it is relatively clear which technologies are the better ones. But early, explicit assessment is necessary, and because typically the number of active participants in the market is small, there is difficulty transmitting experiences among participants. Here a policy can be effective. 


\section{New Scientific Results}

Changes in our scientific knowledge often provide better measures of external effects of various activities. These may raise questions about the social efficiency of dominant technologies. Today, the most obvious example has to do with the effects technologies have on the environment.

Policy can help generate new scientific results by supporting or commissioning research, e.g., research on oil reserves and renewable resource availability. It can also encourage the scientific community to help actively and explicitly evaluate the entire body of evidence. This is often not done explicitly in the normal course of science. At least, it might be fair to say that usually there is not a concerted effort to say "what do we know today, about topic X?" However, one example is the recent report of the Intergovernmental Panel on Climate Change, which was the result of a long study by many climatologists on the evidence regarding global warming.

Another very useful role for policy is to help develop a bridge between the hard sciences and social sciences. There is often a difference between the analysis of a phenomenon from a strictly physical point of view, and from an economic or social point of view. The former is important, but policy is based on the latter. Of course, it is impossible to do the latter without significant knowledge about the former. Thus part of the difficulty in formulating policy is that it necessarily involves considerations drawn from both the hard and social sciences. For renewable energy technologies, one issue would be to measure the economic value of the externalities using engineering measurements of how big the physical externalities are. It is notoriously difficult to generate interdisciplinary research of the kind that would be required to do this in the best possible way. This issue must be addressed not only in the context of renewable energy, but also as a general policy.

The foregoing has been concerned with overturning technological lock-in. We turn now to the second issue, namely, clustering.

\section{Policy Implications of Clustering}

As the market for renewable energy emerges, there will be a competition for market share as there is in any new market. What does the positive feedback literature say about this? We have seen that renewable technologies have several characteristics that make them prone to lock-in. Here we focus not on the competition among technologies, but rather on the competition between firms or national economies.

With the globalization of the economy, and falling trade barriers, policy must address two possibilities: that foreign concerns might capture the domestic market, and the other side of the same coin, the possibility that domestic firms might capture the world market. Early movers have an advantage, so the goal of policy must be to encourage domestic firms to be able to enter the market quickly, and to export aggressively to build a large committed installed base of users, thereby creating an unassailable position. The quality of the technology is less important (within limits of course) than is getting to the market first. (The last statement must be regarded carefully. In a young market there will be considerable fluidity about which firms are the leaders in the field. Leadership position will be driven partly by the perceptions of the users of the technology. A catastrophic failure, such as the recent Kenetech wind turbine blade failures, can have a dramatic impact on the perceptions of users, and thus on the standing of a firm in the market.)

This argument is logically sound. But we must ask the question why, then, were the Japanese, relative latecomers, able to capture the market for electronic consumer devices? There are two responses. First, in one sense they did not. Many of these technologies are not Japanese but are, largely, American. So American technologies won the competition, though American firms may not have (although this is cold comfort to American manufacturing). Second, the argument above does not distinguish between technological development and standardization, and the production of goods based on those technologies. The argument must then be elaborated. 
Imagine the following scenario. Country A, wanting to become a major supplier of renewable energy technologies, initially adopts no specific policy in this area. Other countries adopt policies supporting renewable energy in various ways (perhaps in ways similar to those adopted by the Danish government to support wind power). Firms of other countries develop technology and markets quickly, supported by these policies. Now firms in country $A$ use the research and market development work done by firms in other countries, then enter the market late, but successfully capture market share by using the work of the early entrants. This sounds like an ideal scenario from the point of view of firms in country $A$.

However, this scenario contains a fatal flaw, and uncovering this flaw will also reveal some insights about the potential role of policy. To come second successfully a firm must exploit and improve on the work of other firms. In a market in which technologies are emerging, this means in the first instance exploiting the technological knowledge produced by others. But to do this, a firm must already have invested in human capital, so that its employees are up to speed in the technology and can understand what others have done. In the second instance, improving what others have done, firms must have a source of improvements. Typically, for a new technology, many important improvements to the technology come from its users, who provide information and ideas about the technology that allow suppliers continuously improve it. Thus for a successful industry to emerge, there must be a vibrant community of researchers, producers, and users, within which information about the technology, its properties, its uses, and its features flows freely and quickly. We have already discussed the difficulties of exchanging information, and the role these difficulties play in creating geographic clusters of economic activity.

It is well documented that scientists and engineers in different firms address these difficulties by actively trading information about the processes and technologies on which they are working (Von Hippel [1987] and Schrader [1991]. Schrader discusses information trading among technical managers of competing steel mills.) But in all cases, the issue of credibility is vital to the information being given. Any participant in such a trade must be perceived as serious and a possible source of information himself. The only way to do this is to have generated such information. This observation implies that firms must keep up to speed with emerging technologies, even if they wish to adopt the "coming second" strategy. Without keeping up to speed, even coming second will not be possible. But simply pursuing R\&D will not suffice.

The difficulty with pursuing this policy in isolation is that, especially in a new technology, users play an important role in creating new technological changes. In a study of the machine tool industry, Von Hippel (1976) found that fully $80 \%$ of significant improvements to products were invented, prototyped, and field tested by users rather than by manufacturers. While the machine tool industry might for some reason be a special case, Rosenberg (1982) argues that technical change generated by use of the technology is a widespread phenomenon. Thus "[h]igh quality market information may be as important as basic research for a marketable technology" (Rycroft and Kash 1984). This implies that an industry in which technology is still evolving, must forge a close relationship between users and producers. A producer who is not tightly connected to the community of users will not successfully produce products that are technologically and economically viable.

Thus in order for a knowledge-intensive industry to thrive and compete with industries in other countries, a community of agents must exist. The agents must be present in all stages of the development, production, and use of the technology, and important information must pass freely among them.

Policy then, should promote a community of agents involved in the technology-researchers, producers, and users-all of whom are well connected with each other. Perhaps this could be an international community, in which users may be located throughout the world while at least some producers are in the home country. Research on the flow of ideas suggests that this would be a difficult strategy to carry out successfully. In 
emphasizing the importance of the flow of tacit knowledge, both Patel and Pavitt (1991) and Porter (1990) emphasize the importance of the physical proximity of agents. ${ }^{20}$

These observations suggest that interactions between domestic users and domestic suppliers could be a key element in the success of a national renewables industry in international markets. Domestic markets will be an essential part of the basic technology development, because the feedback from users to manufacturers can be readily exploited. These continuing technology developments will contribute strongly to the global market share of domestic firms. In view of this, the fact that international markets may be larger than domestic ones in the short run increases rather than decreases the importance of a viable domestic market.

Again, it is important to emphasize that this discussion does not imply that policy makers must pick winning technologies. Governments do not know any more about the best choice of technologies than do private sector agents. On the contrary, the above argument suggests that there is value in creating conditions that will encourage and support communities of technical workers, which can have significant advantages in choosing the best technologies and technical approaches for themselves.

20 See note 4 and the accompanying discussion. 


\section{Concluding Remarks}

The idea of lock-in provides insight into situations in which policy action may be beneficial. One kind of case involves escaping existing lock-in situations, such as the present position of conventional energy technologies in many markets. An examination of the dynamics of these markets illustrates that new technologies face barriers that are inherent in the structure of the market. Free markets will generally undersupply "experimentation" with new technologies that would provide valuable information about their costs and performance. This perspective suggests some factors that can help overcome existing lock-in situations, some of which can be enhanced by policy initiatives.

A related phenomenon helps explain why certain industries cluster in geographic regions. Understanding this tendency helps explain how some countries have successfully advanced the position of certain industries in their national economies through conscious efforts at coordination and by nurturing key technical communities. Efforts within the existing scope of government involvement in renewable energy could exploit this effect, helping to nurture a competitive and successful renewable energy industry.

We have shown, then, how renewables are subject to two forms of the lock-in dynamics. Conventional energy sources are already locked in, e.g., in the electricity generation market. The second lock-in dynamic is the potential capture of global renewables markets by foreign suppliers. The discussion illustrates how policy could be useful in both situations. One striking conclusion is that domestic renewable applications could play an essential role in the success of a host country's firms in international markets, through their contribution to ongoing technological advances. 


\section{References}

Arthur, W.B., 1990. "Positive Feedbacks in the Economy," Scientific American, February.

Arthur, W.B., 1988. "Self-Reinforcing Mechanisms in Economics," in Anderson, P.W., and K.J. Arrow, eds., The Economy as an Evolving Complex System, New York: Addison-Wesley.

Arthur, W.B., 1991. "Silicon Valley Locational Clusters: Do Increasing Returns Imply Monopoly?" Mathematical Social Sciences, 19:235-251.

Audretsch, D.B. and M.P. Feldman, 1994. "Knowledge Spillovers and the Geography of Innovation," presented at the 1994 Schumpeter Society Meetings, Muenster.

Babiuch, W., M.A. Bernstein, and D.M. Kline, 1996. "A Framework for Advancing Technology Innovation," Draft, National Renewable Energy Laboratory, Golden CO, July.

BTM Consult ApS, 1995. "Summary: International Wind Energy Development, Status by 1995 and Forecast 1995-2000," prepared for the Danish Energy Agency, R\&D Renewable Energy, December.

Baumol, W., 1995. "Environmental Industries with Substantial Start-Up Costs as Contributors to Trade Competitiveness," Annual Review of Energy and the Environment, 20:71-81.

Cohen, W.M. and D.A. Levinthal, 1989. "Innovation and Learning: The Two Faces of R\&D," Economic Journal, 99:569-596.

Collins, H.M., G.C.S. Collins, A.D.W. Jones, and J.J. Quinn, 1982. "Tacit Knowledge and Scientific Networks," in Science in Context, B. Barnes and D. Edge, eds., MIT Press, pp. 44-64.

Cowan, R, 1990. "Nuclear Power Reactors: A Study in Technological Lock-In," Journal of Economic History, 50:541-567.

Cowan, R., 1991. "Tortoises and Hares: Choice among Technologies of Unknown Merit" The Economic Journal, 101:7-22, July.

Cowan, R. and P. Gunby, 1996. "Sprayed to Death: Path Dependence, Lock-In and Pest Control Strategies," Economic Journal, 106:521-542.

Cowan, R. and S. Hulten, 1996. "Escaping Lock-In: The Case of the Electric Vehicle," Technological Forecasting and Social Change, forthcoming.

David, P. and J. Rosenblum, 1990. "Marshallian Factor Market Externalities and the Dynamics of Industrial Location," Journal of Urban Economics, 28:349-370.

Farrell, J. and G. Saloner, 1985. "Standardization, Compatibility and Innovation," Rand Journal of Economics 16:70-83.

Feldman, M.P., 1994. The Geography of Innovation, Kluwer Academic Publishers.

Foray, D., and A. Gruebler, 1990. "Morphological Analysis, Diffusion and Lock-Out of Technologies: Ferrous Casting in France and the FRG," Research Policy, 9:535-50. 
Gambardella, A., 1992. "Competitive Advantage from In-House Scientific Research: The US Pharmaceutical Industry in the 1980s," Research Policy 21:391-407.

Glaeser, E., H.D. Kallal, J.A. Scheinkman, and A. Schleifer, 1992. "Growth in Cities," Journal of Political Economy, 100(6):1126-1152.

Hirsh, R.F., 1989. Technology and Transformation in the American Electric Utility Industry, Cambridge, England; New York: Cambridge University Press.

Jaffe, A.B., 1989. "Real Effects of Academic Research," American Economic Review, 76:984-1001.

Jaffe, A.B., M. Tratjenberg, and R. Henderson, 1993. "Geographic Localization of Knowledge Spillovers as Evidenced by Patent Citations," Quarterly Journal of Economics, 108(3):557-598.

Johannsson, T.B., H. Kelly, A.K.N. Reddy, and R.H. Williams, 1993. Renewable Energy: Sources for Fuels and Electricity. Washington, $\mathrm{DC}$, and Covelo, CA: Island Press.

Kassler, P., 1994. "Energy for Development," Shell selected paper. London: Shell International Petroleum Company, November.

Krugman, P., 1992. Geography and Trade, Cambridge, MIT Press.

Margolis, S.E. and S. Liebowitz, 1996. We Don't Know Why She Swallowed the Fly: Policy and Path

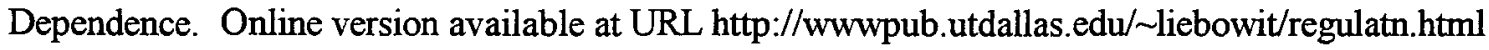

NREL (National Renewable Energy Laboratory), 1996. Data are from the Renewable Energy Data Center. For an introduction to available datasets and publications, see the website http://rredc.nrel.gov/.

Patel, P. and K. Pavitt, 1991. "Technological Strategies of the World's Largest Companies," Science and Public Policy, 18:363-368. December.

Pavitt, K., 1993. "Why Do Firms Do Basic Research?" in Technology and the Wealth of Nations: The Dynamics of Constructed Advantage, D. Foray and C. Freeman, eds., London: Pinter Press.

Porter, M., 1990. The Competitive Advantage of Nations, The Free Press.

Prevezer, M., 1994. “The Dynamics of Industrial Clustering in Biotechnology," London Business School, presented at the 1994 Schumpeter Society Meetings, Muenster.

Prevezer, M. and P. Swann (forthcoming). "A Comparison of the Dynamics of Industrial Clustering in Computing and Biotechnology," Research Policy.

Reback, G., S. Creighton, D. Killam, and N. Nathanson, 1996. "White Paper: Economic and Legal Perspectives Regarding Microsoft's Business Strategy in Light of the Proposed Acquisition of Intuit, Inc." Part of the court record in the antitrust proceeding against Microsoft. A well-formatted copy is available online as URL http://www.cs.adelaide.edu. au/ joswig/upsidefe.html.

Rosenberg, N., 1990. "Why Do Firms Do Basic Research (With Their Own Money)?" Research Policy 19:165-174. 
Rosenberg, N., 1982. Inside the Black Box, Cambridge University Press.

Rosenberg, V., 1967. "Factors Affecting the Preferences of Industrial Personnel and Information Gathering Methods," Information Storage and Retrieval 3(3).

Rycroft, R.W. and D.E. Kash, 1994. "Complex Technology and Community: Implications for Policy and Social Science," Research Policy 23:613-626.

Schrader, S., 1991. "Informal Technology Transfer between Firms: Cooperation through Information Trading: Research Policy, 20:153-170.

Sweeney, G.P., 1987 . Innovation, Entrepreneurship and Regional Development, London: Pinter Press.

Tassey, G., 1992. Technology Infrastructure and Competitive Positions, Kluwer.

Teece, D., 1981. "The Market for Know-How and the Efficient International Transfer of Technology," The Annals of the Academy of Political Social Science.

Teece, D., G. Pisano, and W. Shan 1988. "Joint Ventures and Collaboration in Biotechnology" in International Collaborative Ventures in US Manufacturing, D. Mowery, ed., Ballinger Press.

U.S. DOE (Department of Energy), 1996. Annual Energy Outlook with Projections to 2015, Report DOE/ELA0383(96), January.

Von Hippel, E., 1976. "The Dominant Role of Users in the Scientific Instrument Innovation Process," Research Policy 5:212-239.

Von Hippel, E., 1988. The Sources of Innovation, Oxford University Press.

Von Hippel, E., 1987. "Cooperation between Rivals: Informal Know-How Trading," Research Policy, 16:291-302.

WEC (World Energy Council), 1993. Renewable Energy Resources: Opportunities and Constraints 1990-2020. London: World Energy Council.

Williamson, O., 1985. The Economic Institutions of Capitalism, The Free Press.

World Bank, 1994. Renewable Energy Technology: A Review of the Status and Cost of Selected Technologies, World Bank Technical Paper Number 20. 


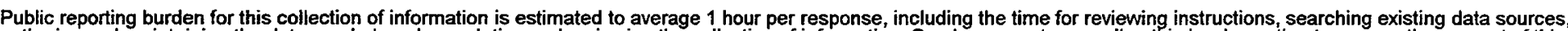

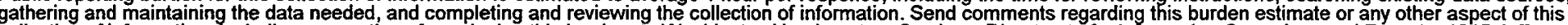

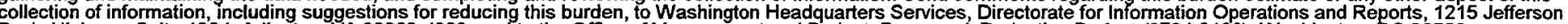
Davis Highway, Suite 1204, Arlington, VA 22202-4302, and to the Office of Management and Budget, Paperwork Reduction Project (0704-0188), Washington, DC 20503.
1. AGENCY USE ONLY (Leave blank)
2. REPORT DATE
3. REPORT TYPE AND DATES COVERED
November 1996
NREL Report

\section{TITLE AND SUBTITLE}

5. FUNDING NUMBERS

The Implications of Potential "Lock-In" in Markets for Renewable Energy

AS027241

6. AUTHOR(S)

Robin Cowan and David Kline

\section{PERFORMING ORGANIZATION NAME(S) AND ADDRESS(ES)}

National Renewable Energy Laboratory

1617 Cole Boulevard

Golden, CO $80401-3393$

9. SPONSORING/MONITORING AGENCY NAME(S) AND ADDRESS(ES)

U.S. Department of Energy

Washington, DC

8. PERFORMING ORGANIZATION REPORT NUMBER

DE97000062

10. SPONSORING/MONITORING AGENCY REPORT NUMBER

NRELTP-460-22112

\section{SUPPLEMENTARY NOTES}

12a. DISTRIBUTION/AVAILABILITY STATEMENT

National Technical Information Service

U.S. Department of Commerce

5285 Port Royal Road

Springfield, VA 22161 12b. DISTRIBUTION CODE

UC-1321

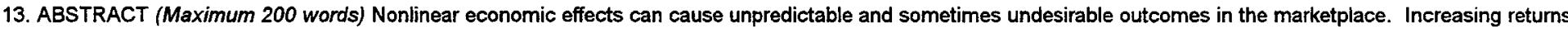

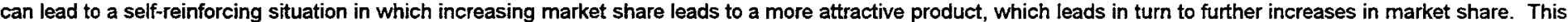
results in "lock-in" of a technology, which cannot be overcome except by a significant shift in technology, consumer tastes, or other market factors.

\section{SUBJECT TERMS}

lock-in, virtuous circle, increasing returns, network externalities
15. NUMBER OF PAGES

24

16. PRICE CODE

19. SECURITY CLASSIFICATION OF ABSTRACT

20. LIMITATION OF ABSTRACT

DECURITY CLASSIFICATION OF REPORT
OF THIS PAGE
Standard Form 298 (Rev. 2-89) Prescribed by ANSI Std. Z39-18 